\title{
QUALIDADE DA ÁGUA PARA IRRIGAÇÃO DE UM CÓRREGO APÓS RECEBER EFLUENTE TRATADO DE ABATE BOVINO
}

\section{MICHAEL S. THEBALDI ${ }^{1}$, DELVIO SANDRI ${ }^{2}$, ALBERTO B. FELISBERTO ${ }^{3}$, MARCO S. DA ROCHA ${ }^{4}$, SEBASTIÃO AVELINO NETO ${ }^{5}$}

\begin{abstract}
RESUMO: A qualidade da água de irrigação é de fundamental importância para não comprometer a qualidade dos produtos e o funcionamento dos equipamentos de irrigação, especialmente quando são diluídos outros compostos. O objetivo deste trabalho foi avaliar a influência do lançamento de efluente de abate de bovinos tratado sobre a qualidade da água para fins de irrigação do Córrego Jurubatuba, Anápolis-GO. As amostras de efluente e água foram obtidas em seis diferentes dias e nos seguintes locais: na descarga do efluente tratado antes do lançamento no córrego - P1, $50 \mathrm{~m}$ a montante do ponto de descarga - P2, $50 \mathrm{~m}$ a jusante do ponto de descarga - P3 e $120 \mathrm{~m}$ a jusante do ponto de descarga - P4. Analisaram-se os sólidos dissolvidos, $\mathrm{pH}$, ferro, dureza, sódio, cálcio, magnésio, manganês, RAS, boro e DBO. Constatou-se risco médio ou alto de entupimento de emissores pelo uso do efluente na irrigação localizada, quando foram considerados $\mathrm{pH}$, sólidos dissolvidos, ferro, dureza e manganês. A água dos locais avaliados no Córrego Jurubatuba apresentou risco médio de entupimento e restrição de uso moderada em relação a problemas de infiltração de água no solo. Em todos os pontos avaliados, as concentrações de DBO foram superiores aos limites para irrigação de vegetais consumidos in natura e cozidos.
\end{abstract}

PALAVRAS-CHAVE: reúso da água, entupimento de emissores, toxicidade.

\section{IRRIGATION WATER QUALITY OF A STREAM AFTER RECEIVING TREATED WASTEWATER FROM CATTLE SLAUGHTER}

\begin{abstract}
Quality of irrigation water is very important to conserve products quality and the operation of irrigation equipment, especially when it contains effluent from residuary sources. The aim of this study was to evaluate the release of treated effluent from cattle slaughter on irrigation water quality of the Jurubatuba Stream, Anápolis - GO, Brazil. The effluent and water samples were taken on six different days and at the following locations: at the discharge of treated effluent before released into the stream - P1, $50 \mathrm{~m}$ upstream from the discharge point - P2, $50 \mathrm{~m}$ downstream from the discharge point - P3 and $120 \mathrm{~m}$ downstream from the discharge point - P4. Variables analyzed were dissolved solids, $\mathrm{pH}$, iron, water hardness, sodium, calcium, magnesium, manganese, SAR, boron and BOD. Medium or high risk of emitters clogging were noticed by possible use of effluent for trickle irrigation when considering variables such as $\mathrm{pH}$, dissolved solids, Iron, Manganese and water hardness. Water at analyzed points in the Jurubatuba Stream presented medium risk of clogging and moderate restriction of use in relation to water infiltration problems. At all analyzed points, the BOD concentrations were higher than the limit for irrigation of vegetables consumed fresh or cooked.
\end{abstract}

KEYWORDS: water reuse, emitters clogging, toxicity.

\footnotetext{
${ }^{1}$ Eng ${ }^{o}$ Agrícola, Doutorando em Recursos Hídricos em Sistemas Agrícolas, Departamento de Engenharia, Universidade Federal de Lavras - MG, micksilveira@gmail.com.

${ }^{2}$ Eng $^{\mathrm{o}}$ Agrícola, Doutor em Engenharia Agrícola, Professor Adjunto, Faculdade de Agronomia e Medicina Veterinária, Universidade de Brasília - DF, sandri@unb.br.

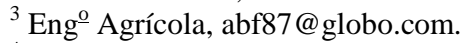

${ }^{4}$ Eng ${ }^{0}$ Agrônomo, Mestre em Engenharia Agrícola, Instituto Brasília Ambiental, Brasília - DF. marcosathler@ yahoo.com.br.

${ }^{5}$ Eng ${ }^{0}$ Agrícola, Doutor em Engenharia Civil, Professor Adjunto, Unidade Universitária de Ciências Exatas e Tecnológicas, Universidade Estadual de Goiás, Anápolis - GO, savneto@gmail.com.

Recebido pelo Conselho Editorial em: 25-10-2010

Aprovado pelo Conselho Editorial em: 16-9-2012
} 


\section{INTRODUÇÃO}

O uso planejado de águas residuárias implica a necessidade de menor captação dos recursos hídricos primários, constituindo-se, portanto, em estratégia eficaz para a conservação desse recurso natural, em seus aspectos qualitativos e quantitativos (MEDEIROS et al., 2007), principalmente quando usado na agricultura, servindo como fonte extra de nutrientes às plantas, auxiliando no desenvolvimento da cultura (SANDRI et al., 2009). Dentre as atividades agrícolas consumidoras de água, a irrigação é a maior delas. Nesta, os consumos específicos variam bastante, a depender do método de irrigação empregado.

Dentre os despejos agroindustriais, o de abate bovino apresenta grande potencial para reúso agrícola devido sua alta carga orgânica e altos conteúdos de nitrogênio e fósforo.

A determinação da qualidade da água para suas diversas finalidades envolve certo grau de complexidade. Faz-se necessário considerar que, além dos fatores naturais, como a interação da água com as rochas, outros fatores, como a interferência da ação do homem, com a introdução de novas substâncias que promovem a alteração da qualidade da água. Dessa forma, a localização de fontes de poluição nas proximidades de poços, nascentes e rios é um fato observado em diversos ambientes (LEAL et al., 2009).

Porém, a utilização de águas residuárias primárias ou secundárias, ou mesmo águas que não recebem nenhum tipo de esgoto, não pode ocorrer à revelia em irrigação. A água de irrigação é de fundamental importância para não comprometer a qualidade dos produtos e o funcionamento dos equipamentos de irrigação, especialmente quando contêm efluentes. Existem vários critérios de qualidade da água para irrigação, como exemplo, em águas residuárias são fundamentais aspectos sanitários, e no caso da irrigação localizada, um fator de qualidade essencial é o risco de obstruções. A presença de alguns constituintes, como o sódio $(\mathrm{Na})$ e metais pesados, é indesejável (MARQUES et al., 2006).

Para DUARTE et al. (2008), a irrigação com esgoto sem tratamento adequado pode ser nociva ao meio ambiente, à saúde humana, ao solo, aos aquíferos e às culturas irrigadas; no entanto, segundo HEIDARPOUR et al. (2007), a crescente necessidade de água, nas regiões áridas do mundo, resultou na necessidade do uso de águas residuais para a aplicação em agricultura e paisagismo. Segundo SOUSA et al. (2006), a utilização de lagoas de estabilização é o melhor método de tratamento de efluentes, principalmente quando esse efluente possui o objetivo de ser aplicado na agricultura.

$\mathrm{Na}$ região de despejo do efluente proveniente do frigorífico estudado, encontram-se diversas pequenas propriedades rurais instaladas nas margens do Córrego Jurubatuba, voltadas principalmente à produção de hortículas. Nas áreas irrigadas dessas propriedades, utiliza-se, sobretudo, a aspersão convencional. Se esse tipo de sistema de irrigação for utilizado com água poluída, principalmente em hortaliças folhosas, pode causar problemas de contaminação e aumentar o risco de doenças.

Diante do exposto, o objetivo deste trabalho foi avaliar a influência do lançamento de efluente de abate de bovinos tratado sobre a qualidade da água para fins de irrigação do Córrego Jurubatuba, em Anápolis - GO.

\section{MATERIAL E MÉTODOS}

Para investigar uma possível mudança na qualidade da água do Córrego Jurubatuba, em função do lançamento do efluente tratado, amostras de água foram coletadas em quatro pontos, como mostrado na Figura 1: P1 (descarga do efluente tratado, antes do lançamento no córrego); P2 (50 metros a montante do ponto de descarga); P3 (50 metros a jusante do ponto de descarga), e P4 (120 metros à jusante do ponto de descarga), com seis repetições (coletas), realizadas nos dias 10; $17 ; 24$ e 31 de agosto e 14 e 21 de setembro, entre 7 e 8 horas. 
O efluente tratado utilizado no estudo provinha da estação de tratamento de esgotos (ETE) de um frigorífico localizado no município de Anápolis-GO. A ETE situa-se nas coordenadas geográficas $16^{\circ} 19^{\prime} 17^{\prime}$ S e 48 $59^{\prime} 33^{\prime}$ ' W, sendo constituída de três lagoas de estabilização em série, das quais duas anaeróbias (volumes de $9.867,90 \mathrm{~m}^{3}$ e $8.107,44 \mathrm{~m}^{3}$ ) e uma lagoa facultativa (volume de $12.900,00 \mathrm{~m}^{3}$ ). Após o tratamento, o efluente do sistema é lançado no Córrego Jurubatuba.

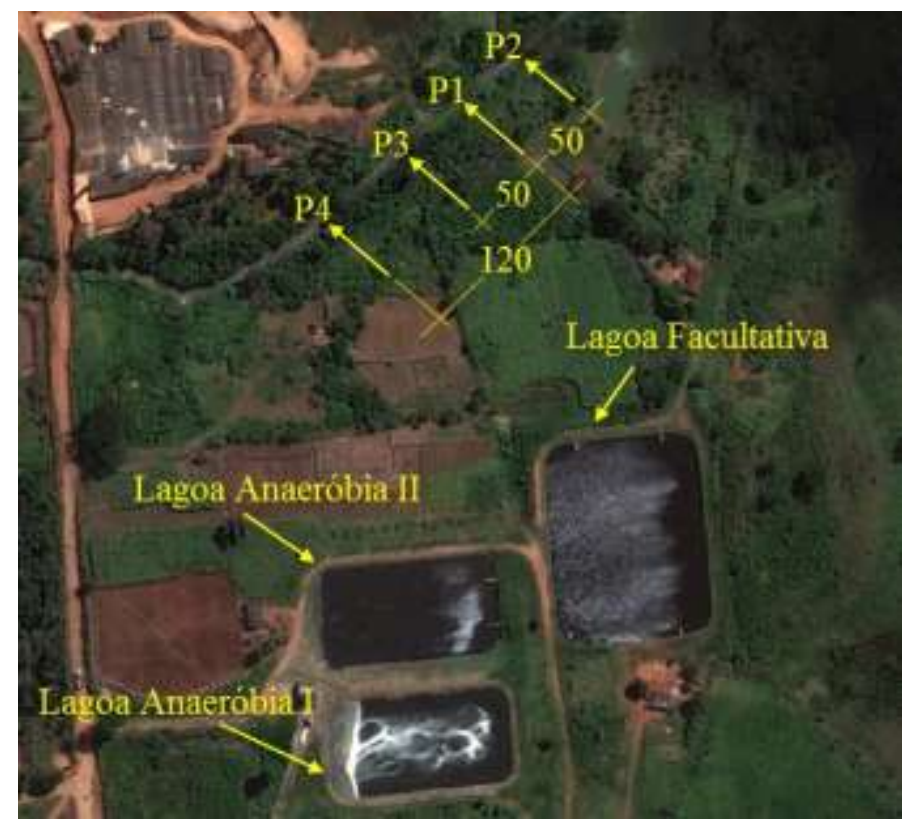

FIGURA 1. Localização dos pontos de coleta de amostras de água. Location of water collecting points.

Na Tabela 1, encontra-se a quantidade de cabeças de gado abatidas por semana a partir de sete dias antes do início das coletas de amostra de efluente e água. O número médio de cabeças de gado abatidas por semana, a partir do início de 2009 até o início do experimento, foi praticamente o mesmo dos apresentados durante as amostragens.

TABELA 1. Cabeças de gado abatidas por semana a partir de sete dias antes do início das coletas de amostra de efluente e água. Number of cattle slaughtered per week at seven previous days before sampling effluent and water.

\begin{tabular}{cccc}
\hline Intervalo de Dias & $\begin{array}{c}\text { Quantidade de Cabeças } \\
\text { de Gado Abatidas }\end{array}$ & $\begin{array}{c}\text { Volume Afluído na ETE } \\
\left(\mathrm{m}^{3}\right)\end{array}$ & $\begin{array}{c}\text { Tempo de Detenção } \\
\text { Hidráulico Teórico } \\
\text { (semanas) }\end{array}$ \\
\hline 3 a 9/8/2009 & 1.534 & $3.835,0$ & 8,05 \\
10 a 16/8/2009 & 1.455 & $3.637,5$ & 8,49 \\
17 a 23/8/2009 & 1.698 & $4.245,0$ & 7,27 \\
24 a 30/8/2009 & 1.526 & $3.815,0$ & 8,09 \\
31/8 a 6/9/2009 & 1.750 & $4.375,0$ & 7,06 \\
07 a 13/9/2009 & 1.845 & $4.612,5$ & 6,69 \\
14 a 20/9/2009 & 2.123 & $5.307,5$ & 5,82 \\
\hline
\end{tabular}

O número de cabeças de gado abatidas no frigorífico encontra-se na Figura 2, no período de 3 de agosto a 20 de setembro de 2009. 




FIGURA 2. Evolução do número de cabeças de gado abatidas a partir de sete dias antes do início das coletas de amostra de água. Evolution of slaughtered cattle from seven days before the beginning of water sampling.

No decorrer do experimento, foram obtidos dados de precipitação gerados pelo Sistema de Meteorologia e Hidrologia do Estado de Goiás, provenientes de uma estação meteorológica automatizada, instalada na cidade de Anápolis. No período de 9 de agosto a 20 de setembro de 2009, ocorreram precipitações apenas nos dias 23 de agosto e 20 de setembro, de $0,5 \mathrm{~mm}$ e $5,75 \mathrm{~mm}$, respectivamente.

Foram analisados os parâmetros sólidos dissolvidos totais (SDT), pH, ferro, dureza, sódio, cálcio, magnésio, razão de adsorção de sódio (RAS), manganês, boro e demanda bioquímica de oxigênio (DBO).

A condutividade elétrica foi determinada por condutivímetro digital portátil com compensação automática de temperatura e escala de medição entre $0,00 \mathrm{dS} \mathrm{m}^{-1}$ e $19,99 \mathrm{dS} \mathrm{m}^{-1}$. A resolução do aparelho era de $0,01 \mathrm{dS} \mathrm{m}^{-1}$, com precisão $\pm 2 \%$. O pH foi medido com pHmetro portátil microprocessado. Ambos os parâmetros foram determinados em campo.

A concentração de ferro foi obtida seguindo o procedimento de MERCK (1972). A concentração de manganês foi obtida seguindo o procedimento descrito por FRIES \& GETROST (1977). As concentrações de DBO, dureza, cálcio, magnésio e boro foram determinadas seguindo metodologias apresentadas em APHA (1995). A concentração de sódio foi obtida em um espectrofotômetro de absorção atômica, modelo AAnalyst 200, da marca Perkin Elmer.

Para todos estes parâmetros, menos a DBO, dureza total e sódio, a concentração em $\mathrm{mg} \mathrm{L}^{-1}$ foi obtida em um fotocolorímetro de bancada, modelo Superfoto, marca Alfakit, com resolução de $0,001 \mathrm{mg} \mathrm{L}^{-1}$ para concentração e de 0,001 para absorvância e precisão de $2 \%$.

A RAS foi calculada pela eq.(1):

$$
\mathrm{RAS}=\frac{\mathrm{Na}^{++}}{\sqrt{\frac{\mathrm{Ca}^{++}+\mathrm{Mg}^{++}}{2}}}
$$

em que,

RAS - razão de adsorção de sódio;

$\mathrm{Na}^{+}$- concentração do íon sódio, meq $\mathrm{L}^{-1}$;

$\mathrm{Ca}^{++}$- concentração do íon cálcio, meq $\mathrm{L}^{-1}$;

$\mathrm{Mg}^{++}$- concentração do íon magnésio, meq $\mathrm{L}^{-1}$.

Os resultados obtidos pelas análises foram comparados aos critérios adotados na interpretação 
da qualidade das águas de irrigação apresentados por AYERS \& WESTCOT (1985), NAKAYAMA \& BUCKS (1986), METCALF \& EDDY (1991) e USEPA (1992). As concentrações dos parâmetros de qualidade da água foram comparadas pelos testes $\mathrm{F}$ e Tukey, a 5\% de significância, e utilizados gráficos de box-plot para auxiliar na interpretação dos dados obtidos.

\section{RESULTADOS E DISCUSSÃO}

Além de outros fatores, a qualidade do efluente tratado pode variar em função da carga orgânica dos esgotos afluentes à estação de tratamento, sendo esta diretamente relacionada ao fluxo de abate (animais abatidos/dia). Percebe-se, na Tabela 1, que, durante o período de coleta de amostras de efluente, não houve grande variação no fluxo semanal de abate. Pela Figura 3, nota-se que não houve abates em vários dias do período analisado, fato que pode modificar a qualidade do efluente final das lagoas. Mesmo apresentando um alto tempo de detenção hidráulica, em função do número de abates (Tabela 1), cargas afluentes que passem por curtos-circuitos hidráulicos na ETE promovem respostas rápidas nas concentrações dos parâmetros avaliados.

Outro fator que pode alterar as concentrações dos parâmetros estudados é a precipitação ocorrida na região dos pontos de coleta de água, que está diretamente ligada à maior diluição do efluente recebido pelo Córrego Jurubatuba, em razão do aumento da vazão do corpo hídrico, gerando uma eventual redução na concentração dos parâmetros estudados. No caso deste estudo, a influência da precipitação pluvial não pode ser considerada na avaliação da qualidade da água e do efluente, já que, na maioria dos dias de coleta, não houve precipitações efetivas na região de amostragem.

Os resultados das análises de variância realizadas para os parâmetros estudados e testes de comparação de médias pelo teste F, a 5\% de probabilidade, são apresentados na Tabela 2.

TABELA 2. ANOVA e resultado dos testes de média para os parâmetros $\mathrm{CE}, \mathrm{pH}, \mathrm{Fe}$, dureza, Na, $\mathrm{Ca}, \mathrm{Mg}, \mathrm{RAS}, \mathrm{Mn}, \mathrm{B}$ e $\mathrm{DBO}$. ANOVA and average tests results for parameters EC, pH, Iron, hardness, Na, Ca, Mg, SAR, Mn, B and BOD.

\begin{tabular}{|c|c|c|c|c|c|c|c|}
\hline \multirow{2}{*}{ Parâmetro } & \multicolumn{4}{|c|}{ Pontos de Análise } & \multirow[b]{2}{*}{ DesvPad } & \multirow[b]{2}{*}{$\mathrm{F}$} & \multirow[b]{2}{*}{ C.V. $(\%)$} \\
\hline & $\mathrm{P} 1$ & $\mathrm{P} 2$ & $\mathrm{P} 3$ & $\mathrm{P} 4$ & & & \\
\hline$\overline{\mathrm{CE}}$ & $1,56 \mathrm{~A}$ & $0,303 \mathrm{~B}$ & $0,310 \mathrm{~B}$ & $0,307 \mathrm{~B}$ & 0,2046 & $56,43^{*}$ & 32,98 \\
\hline $\mathrm{pH}$ & 7,68 & 7,63 & 7,58 & 7,53 & 0,2053 & $0,59 \mathrm{~ns}$ & 2,70 \\
\hline $\mathrm{Fe}$ & $2,843 \mathrm{~A}$ & $0,312 B$ & $0,335 \mathrm{~B}$ & $0,396 \mathrm{~B}$ & 0,2630 & $135,26^{*}$ & 27,07 \\
\hline Dureza & $566,67 \mathrm{~A}$ & $120,33 B$ & $121,33 \mathrm{~B}$ & $121,00 \mathrm{~B}$ & 117,4027 & $21,63^{*}$ & 50,53 \\
\hline $\mathrm{Ca}$ & $5,000 \mathrm{~A}$ & $1,288 \mathrm{~B}$ & $1,293 \mathrm{~B}$ & $1,287 \mathrm{~B}$ & 1,382 & $10,81^{*}$ & 62,33 \\
\hline $\mathrm{Mg}$ & $6,333 \mathrm{~A}$ & $1,113 \mathrm{~B}$ & $1,133 \mathrm{~B}$ & $1,077 \mathrm{~B}$ & 1,180 & $29,41^{*}$ & 48,89 \\
\hline $\mathrm{Na}$ & $6,558 \mathrm{~A}$ & $0,583 \mathrm{~B}$ & $0,613 \mathrm{~B}$ & $0,603 B$ & 0,9367 & $60,70^{*}$ & 44,83 \\
\hline RAS & $2,88 \mathrm{~A}$ & $0,53 \mathrm{~B}$ & $0,55 \mathrm{~B}$ & $0,55 \mathrm{~B}$ & 0,4686 & $37,37 *$ & 41,50 \\
\hline $\mathrm{Mn}$ & $1,072 \mathrm{~A}$ & $0,060 \mathrm{~B}$ & $0,187 \mathrm{~B}$ & $0,037 \mathrm{~B}$ & 0,3060 & $15,60 *$ & 90,32 \\
\hline$\underline{B}$ & $0,097 \mathrm{~A}$ & $0,000 \mathrm{~B}$ & $0,024 \mathrm{AB}$ & $0,000 \mathrm{~B}$ & 0,0456 & $6,11 *$ & 151,14 \\
\hline $\mathrm{DBO}$ & $3,41 \mathrm{~A}$ & $73,68 \mathrm{~B}$ & $26,71 \mathrm{AB}$ & $71,21 \mathrm{~B}$ & 55,6114 & $7,45^{*}$ & 46,83 \\
\hline
\end{tabular}

Em que: CE: condutividade elétrica $\left(\mathrm{mg} \mathrm{L}^{-1}\right)$; Fe: ferro $\left(\mathrm{ml} \mathrm{L}^{-1}\right)$; Dureza $\left(\mathrm{ml} \mathrm{L}^{-1}\right)$; Ca: cálcio (meq L $\left.{ }^{-1}\right)$; $\mathrm{Mg}$ : magnésio (meq L $\left.\mathrm{L}^{-1}\right) ; \mathrm{Na}$ : sódio (meq L $\mathrm{L}^{-1}$ ); Mn: manganês ( $\mathrm{mg} \mathrm{L}^{-1}$ ); B: boro $\left(\mathrm{mg} \mathrm{L}^{-1}\right)$; DBO: demanda bioquímica de oxigênio (mg L $\left.{ }^{-1}\right)$; DesvPad: desvio-padrão, F: teste F; cv: coeficiente de variação; ns: não significativo, *: significativo pelo teste $\mathrm{F}$ a $5 \%$ de probabilidade. Valores na horizontal seguidos por mesma letra maiúscula não diferem estatisticamente; pelo teste de Tukey, a 5\% de probabilidade.

São apresentados nas Figuras 3A, 3B, 3C e 3D os gráficos de box-plot dos parâmetros sólidos dissolvidos totais, $\mathrm{pH}$, ferro e dureza, respectivamente. 

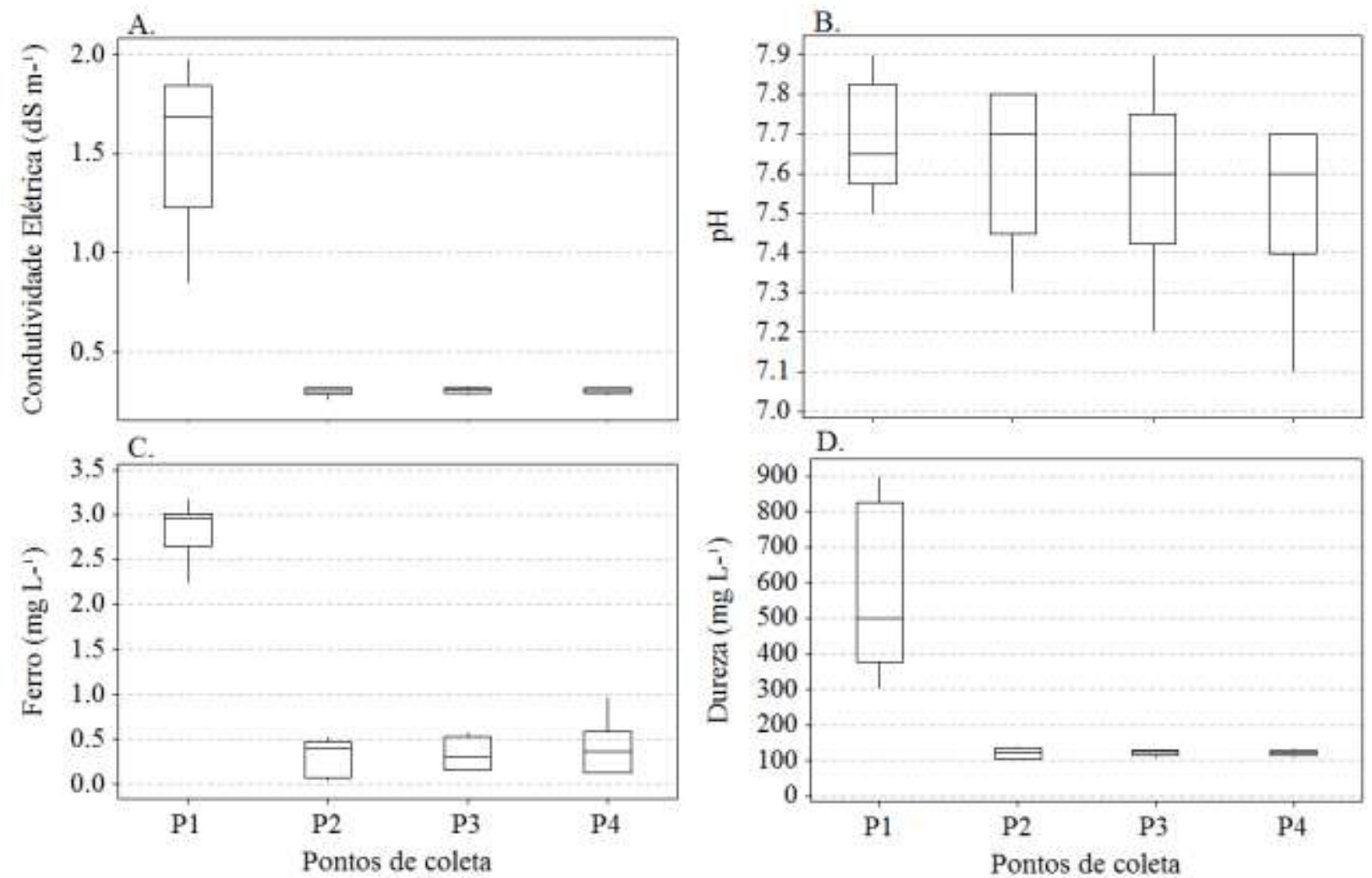

FIGURA 3. Box-plot das concentrações de condutividade elétrica (A), pH (B), ferro (C) e dureza (D) obtidas nos pontos P1, P2, P3 e P4. Box-plot of the concentrations of electrical conductivity (a), pH (B), iron (C) and hardness (D) obtained at points P1, P2, P3 and P4.

$\mathrm{O}$ teste $\mathrm{F}$ realizado nos dados obtidos de condutividade elétrica mostrou-se significativo, a 5\% de probabilidade (Tabela 2), sendo maior no ponto P1 em relação a todos os outros pontos estudados. Como mostrado na Figura 3A, em P1, houve maior variabilidade dos dados obtidos, mostrando diferentes concentrações de íons dissolvidos no efluente tratado. Para os demais pontos, houve grande constância dos valores obtidos.

Em P1, há restrição de uso moderada para irrigação devido à salinidade e, para os demais pontos, não há restrição de uso, segundo classificação de AYERS \& WESTCOT (1985). FRANCO \& HERNANDEZ (2009) avaliaram a qualidade da água para irrigação na microbacia do Córrego Coqueiro, em ponto localizado na cidade de Palmeiras d'Oeste-SP e obtiveram média de 0,187 dS $\mathrm{m}^{-1}$ de condutividade elétrica, mostrando maior presença de sais no Córrego Jurubatuba.

O gráfico box-plot dos valores de $\mathrm{pH}$ obtidos na água para os diversos pontos de análise é apresentado na Figura 3B. O efluente tratado foi o que apresentou menor variação de $\mathrm{pH}$ durante o monitoramento, porém todos os pontos permaneceram em faixa considerada neutra.

$\mathrm{O} \mathrm{pH}$, dentre todos os parâmetros analisados, foi o que apresentou menor coeficiente de variação, não apresentando variação significativa entre o valor do efluente tratado $(\mathrm{P} 1)$ e as amostras do Córrego Jurubatuba (P2, P3 e P4) (Tabela 2). Todos os valores de pH ficaram dentro do padrão descrito por AYERS \& WESTCOT (1985), sobre critérios adotados na interpretação da qualidade das águas de irrigação, porém apresentando risco mediano de entupimento de emissores (NAKAYAMA \& BUCKS, 1986).

DUARTE et al. (2008) citam que a concentração $\mathrm{H}^{+}$e $\mathrm{OH}^{-}$, contida nas águas de irrigação, pode exercer influência na disponibilidade e absorção de nutrientes por parte das plantas, na estrutura e propriedades do solo e nos sistemas de irrigação. BAUMGARTNER et al. (2007), em efluente de suinocultura tratado por lagoas de estabilização, obtiveram 8,13 de valor de $\mathrm{pH}$, superior 
ao avaliado em P1, de 7,68. Valores de $\mathrm{pH}$ fora da faixa neutra podem influenciar na eficiência do sistema de tratamento de esgoto.

Os resultados de $\mathrm{pH}$ encontrados no Córrego Jurubatuba foram superiores aos obtidos por MACHADO et al. (2005), que, em média, obtiveram o valor de 6,54 para este parâmetro no Rio Paraibuna, Juiz de Fora, em trecho influenciado por despejos domésticos e próximos ao avaliado por MENEZES et al. (2009) que obtiveram 7,2, na Bacia Hidrográfica do Rio São Domingos-RJ, marcado por fontes de contaminação antrópica.

Em todos os pontos analisados, a concentração de ferro total apresentou pouca variação para os diversos dias de coleta de água (Figura 3C). A concentração total de ferro em P1 foi superior às concentrações nos demais pontos estudados, não alterando, portanto, o teor de ferro total já presente no Córrego Jurubatuba (Tabela 2). Mesmo com a grande concentração de ferro no efluente tratado, devido à presença de sangue no resíduo do frigorífico, o Córrego Jurubatuba mostrou boa capacidade de assimilação deste elemento.

O teor de ferro total possui relevância ao se analisar a qualidade da água para irrigação. Segundo classificação de NAKAYAMA \& BUCKS (1986), a água analisada em P1, se utilizada em irrigação, apresenta alto risco potencial de entupimento de emissores, enquanto a água dos demais pontos apresenta risco intermediário. Todas as concentrações obtidas foram inferiores às citadas como máximas por METCALF \& EDDY (1991).

FAVRET \& CRUZ (2007) avaliaram a qualidade da água utilizada para irrigação de hortaliças, na região de Botucatu-SP, e encontraram concentração de $0,6 \mathrm{mg} \mathrm{L}^{-1}$ de ferro, valor superior aos encontrados em P2, P3 e P4.

$\mathrm{O}$ ponto $\mathrm{P} 1$ foi o que apresentou maior variação dos valores encontrados ao longo do experimento de dureza total (Figura 3D). Os demais pontos mostram boa uniformidade de dados para este parâmetro, e analisando-se a Tabela 2, tem-se maior concentração de dureza total em P1, em comparação com P2, P3 e P4.

Segundo classificação de NAKAYAMA \& BUCKS (1986), a água de P1 apresentou alto risco potencial de entupimento de emissores. Em contrapartida, o risco de entupimento das águas dos pontos analisados do Córrego Jurubatuba é reduzido, assim como nos dados avaliados por FRANCO \& HERNANDEZ (2009), que encontraram a concentração de $102 \mathrm{mg} \mathrm{L}^{-1}$ de dureza, avaliando a qualidade da água para irrigação na microbacia do Córrego Coqueiro-SP. Águas duras podem causar incrustações em tubulações de água quente como também em motobombas utilizadas em irrigação.

São apresentados, nas Figuras 4A, 4B, 4C e 4D, os gráficos e box-plot das concentrações dos parâmetros cálcio, magnésio, sódio e RAS, respectivamente.

Nos valores encontrados para cálcio e magnésio em $\mathrm{P} 1$, houve maior variação das concentrações obtidas, contrastando com os demais pontos de estudo, nos quais se nota mais uniformidade nos dados obtidos ao longo dos dias de amostragem (Figuras 4A e 4B). As concentrações médias de cálcio e magnésio em $\mathrm{P} 1$ foram maiores que nos pontos de coleta localizados no Córrego Jurubatuba (Tabela 2).

Apurando a qualidade do efluente doméstico de uma ETE composta por lagoas de estabilização do tipo Australiano, para reúso na cultura da cana-de-açúcar, GOMES et al. (2009) obtiveram concentração de 0,707 meq $\mathrm{L}^{-1}$ de cálcio e $0,414 \mathrm{meq} \mathrm{L}^{-1}$ de magnésio, resultados inferiores aos encontrados destes parâmetros no ponto $\mathrm{P} 1$ deste estudo.

Os valores observados de sódio nos pontos de análise localizados no Córrego Jurubatuba apresentaram grande uniformidade, como visto na Figura 4C. Já P1 apresentou maior variedade de concentrações obtidas, sendo a concentração média obtida no efluente tratado maior que as concentrações nos pontos P2, P3 e P4 (teste F, Tabela 2). 

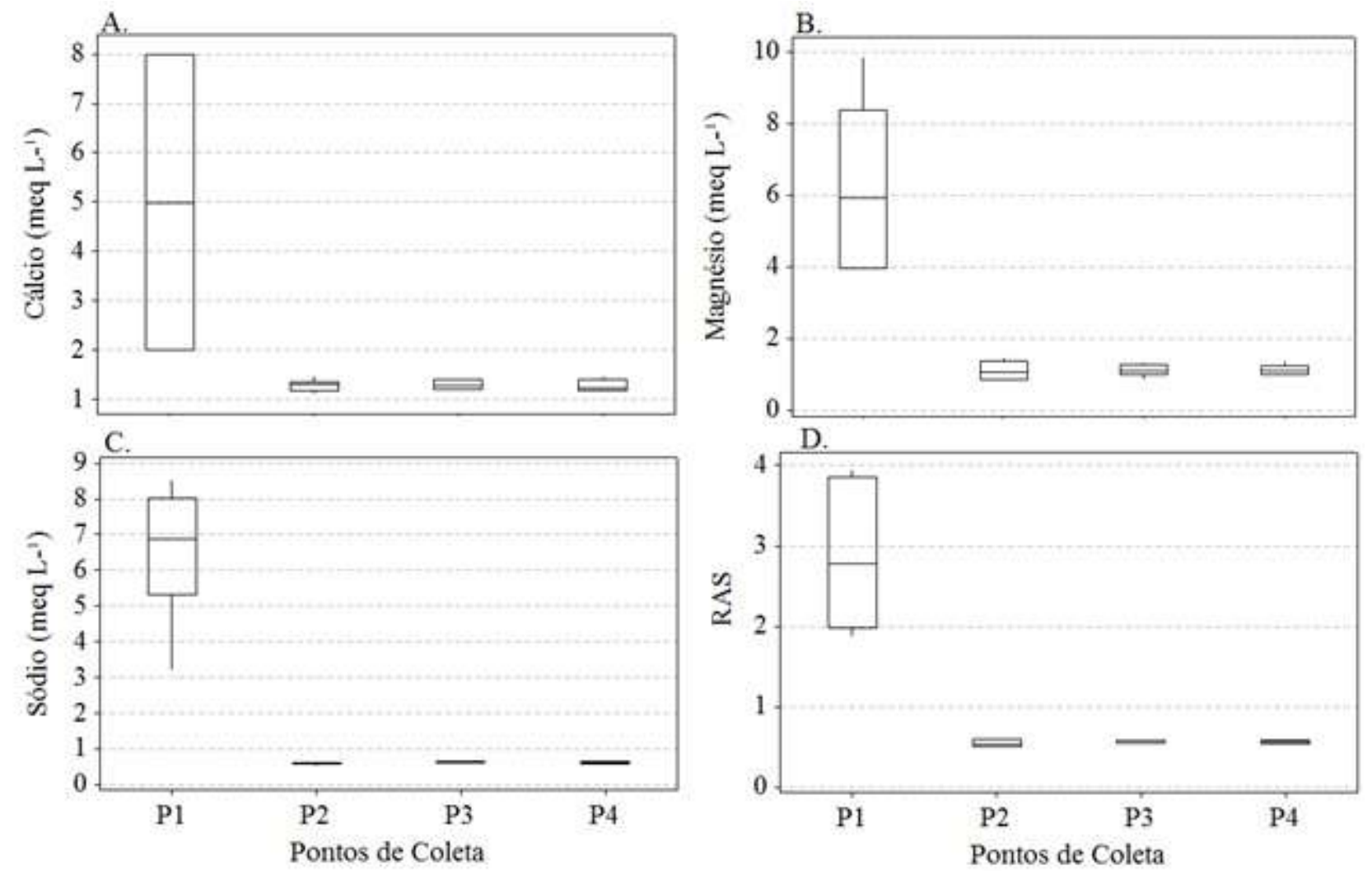

FIGURA 4. Box-plot das concentrações de cálcio (A), magnésio (B), sódio (C) e RAS (D) obtidas para os pontos P1, P2, P3 e P4. Box-plot of the concentrations of calcium (A), magnesium (B), sodium (C) and SAR (D) obtained at points P1, P2, P3 and P4.

Nos pontos P2, P3 e P4, foram obtidos valores muito próximos de RAS ao longo dos dias de análise da qualidade da água (Figura 3D). Avaliando os valores presentes no efluente tratado (P1, Figura 4D) durante a realização do experimento, notam-se valores com maior variabilidade.

As médias do teor de sódio e da RAS de $\mathrm{P} 1$ foram superiores às médias desses parâmetros nos demais pontos avaliados, porém as concentrações avaliadas nos pontos do Córrego Jurubatuba foram iguais (Tabela 2), mostrando não haver interferência do efluente tratado sobre a concentração de sódio e sobre a RAS à jusante do lançamento.

De acordo com AYERS \& WESTCOT (1985), não há restrição ao uso do efluente tratado em relação a problemas de infiltração de água no solo. Já para os demais pontos, a restrição ao uso é moderada.

A toxicidade às plantas pela presença de sódio na água de irrigação também é avaliada por AYERS \& WESTCOT (1985); só que, para o parâmetro sódio, os graus de restrição são de acordo com o método de irrigação que será realizado. Nenhum dos pontos avaliados apresenta restrição para irrigação por superfície, enquanto o efluente tratado apresenta restrição moderada em irrigação por aspersão, e os demais pontos não apresentam restrição.

SOUSA et al. (2009), analisando efluentes domésticos tratados por sistema australiano de lagoas de estabilização, e SANDRI et al. (2006), avaliando efluente doméstico tratado em reator anaeróbio, seguido de leito de macrófitas utilizado em irrigação, observaram concentração de sódio de 1,85 e 0,81 , respectivamente, mostrando menor quantidade deste sal em efluente doméstico, comparado ao efluente de abate bovino.

NOBRE et al. (2009) avaliaram a qualidade de efluente doméstico tratado para irrigação, encontrando valor de 4,166 para RAS, quase o dobro do encontrado neste estudo. 
São apresentados, na Figura 5, os gráficos e box-plot dos concentrações dos parâmetros manganês, boro e DBO.
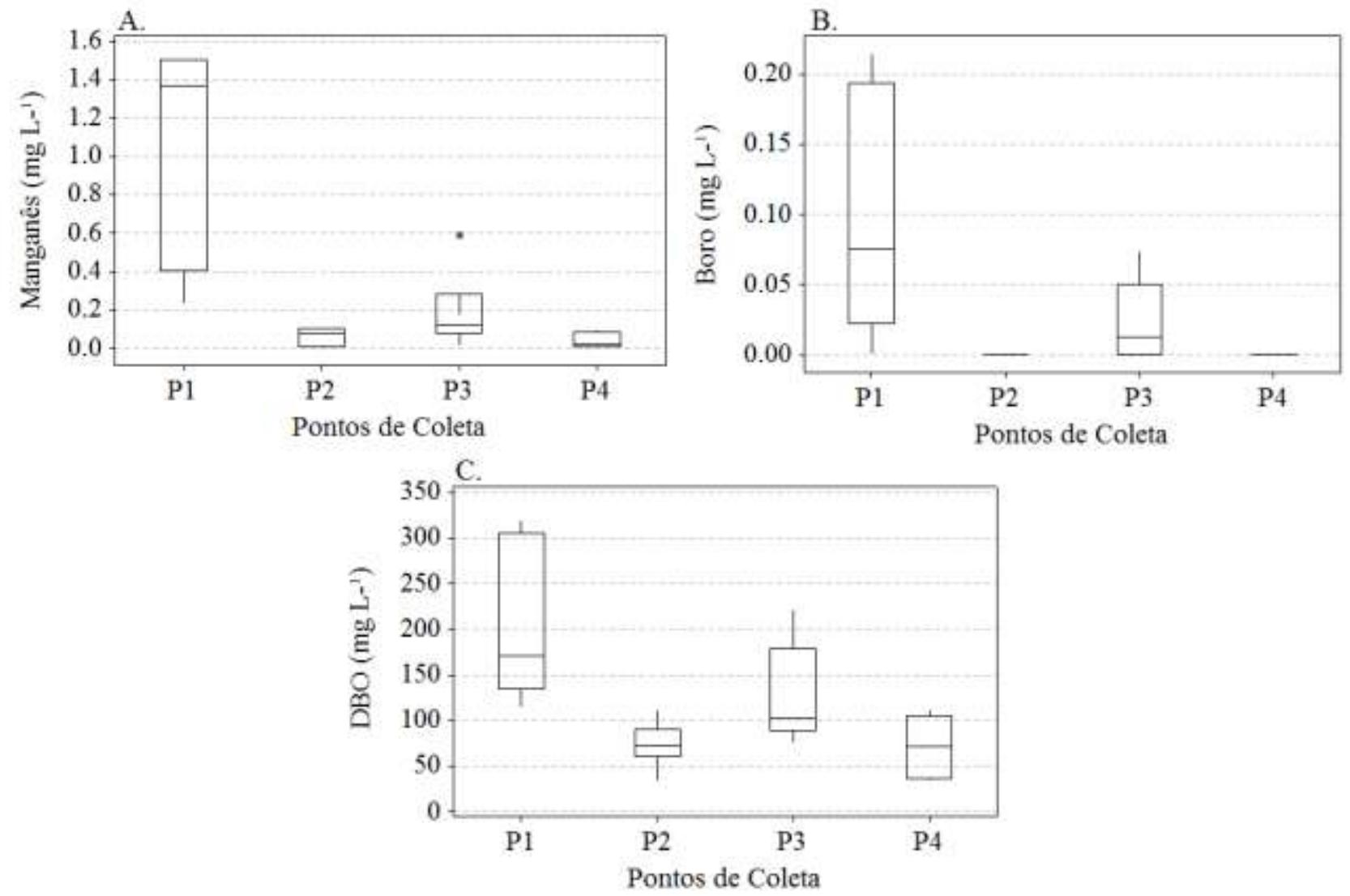

FIGURA 5. Box-plot das concentrações de manganês (A), boro (B) e DBO (C) obtidas para os pontos P1, P2, P3 e P4. Box-plot of the concentrations of manganese (A), boron (B) and BOD (C) obtained at points P1, P2, P3 and P4.

As concentrações avaliadas de manganês em P1 apresentaram alta variabilidade, como pode ser notado na Figura 5A. Não houve diferença significativa nas concentrações de manganês nos pontos avaliados do Córrego Jurubatuba, sendo a presença deste elemento significativamente superior aos demais em P1. Mesmo não havendo diferença significativa entre P2 e P3, nota-se tendência de elevação da concentração de manganês no ponto P3, em função da mistura da água do Jurubatuba com o efluente tratado (Tabela 2).

Segundo NAKAYAMA \& BUCKS (1986), a água dos pontos P1 e P3 apresentam risco médio de entupimento de emissores pela presença de manganês, e P2 e P4, risco reduzido. METCALF \& EDDY (1991) apresentam como quantidade máxima de manganês em água de irrigação $0,2 \mathrm{mg} \mathrm{L}^{-1}$, comentando que este elemento, em concentração de alguns décimos até poucos $\mathrm{mg} \mathrm{L}^{-1}$, pode ser tóxico às culturas em solos ácidos. Portanto, a utilização da água de P1 para irrigação deve ser feita com cautela.

MEDEIROS et al. (2007) irrigaram gérberas com efluente doméstico sem tratamento, apenas diluído na água de um córrego em Campina Grande-PB, e detectaram concentração de $0,02 \mathrm{mg} \mathrm{L}^{-1}$, o que demonstra a alta concentração deste elemento no efluente tratado de abate bovino porém este valor esteve próximo dos avaliados nos pontos do Córrego Jurubatuba.

Foi obtida grande variedade de concentrações de boro em P1, mas estas variaram dentro de uma pequena faixa $\left(0,000 \mathrm{mg} \mathrm{L}^{-1}\right.$ a $\left.0,215 \mathrm{mg} \mathrm{L}^{-1}\right)$. Em P2 e P4, não foi detectada presença de boro. Já em P3, a concentração deste elemento variou de $0,000 \mathrm{mg} \mathrm{L}^{-1}$ a $0,042 \mathrm{mg} \mathrm{L}^{-1}$ (Figura 5B).

Em média, a concentração de boro em P1 foi igual à encontrada em P3 e maior em comparação com os pontos P2 e P4 (Tabela 2), mostrando uma influência positiva do efluente 
descartado sobre a concentração deste elemento no corpo hídrico. Porém, já no ponto distante $120 \mathrm{~m}$ (P4) da mistura do efluente com a água do córrego, o valor encontrado é igual ao avaliado cinquenta metros a montante de P1.

Comparando-se as médias de concentração de boro apresentadas na Tabela 2 com os critérios adotados na interpretação da qualidade das águas de irrigação definidos por AYERS \& WESTCOT (1985), não há risco de utilização da água de todos os pontos analisados, avaliando-se o grau de toxicidade que pode ser causado pela presença de boro.

O gráfico de box-plot do parâmetro DBO contém grande variação dos valores na água para todos os pontos (Figura 5C). Os pontos P1 e P3 apresentaram os maiores valores como também as maiores variações.

A DBO média do efluente tratado foi igual à encontrada no P3 e maior que as encontradas nos pontos $\mathrm{P} 2$ e P4 (Tabela 2). Isso demonstra que, após cinquenta metros do ponto de lançamento do efluente, não há queda significativa no valor de $\mathrm{DBO}$, sendo a autodepuração neste trecho insuficiente. A alta DBO a montante do ponto de lançamento do efluente da indústria frigorífica mostra a possibilidade da existência de despejos domésticos e/ou industriais no córrego. Este fato pode ser explicado pelo fato de a microbacia do Córrego Jurubatuba possuir uso urbano - rural.

A DBO do efluente tratado (P1) encontra-se fora dos padrões para reúso da água propostos por USEPA (1992) para irrigação de vegetais consumidos crus $\left(10 \mathrm{mg} \mathrm{L}^{-1}\right)$ e cozidos $\left(30 \mathrm{mg} \mathrm{L}^{-1}\right)$. JOSÉ et al. (2009) aplicaram efluente de abatedouro bovino tratado em lagoas de estabilização sobre a cultura do milho e obtiveram concentração média de DBO de $641 \mathrm{mg} \mathrm{L}^{-1}$, valor bem superior aos encontrados em P1.

\section{CONCLUSÕES}

Constatou-se risco médio ou alto de entupimento de emissores pelo uso do efluente na irrigação localizada para $\mathrm{pH}$, condutividade elétrica, ferro, dureza e manganês.

A água dos pontos avaliados no Córrego Jurubatuba apresentou risco médio de entupimento e restrição de uso moderada em relação a problemas de infiltração de água no solo.

Em todos os pontos avaliados, as concentrações de DBO foram superiores aos limites para irrigação de vegetais consumidos in natura e cozidos. Assim, o efluente tratado e a água do Córrego Jurubatuba, nos pontos avaliados, não deve ser utilizada em irrigação.

\section{AGRADECIMENTOS}

Ao $\mathrm{CNPq}$, pela concessão de auxílio financeiro em prol da realização desta pesquisa (Processo: 552363/2007-3).

\section{REFERÊNCIAS}

APHA. American Public Health Association. Standard methods for examination of water and wastewater. $19^{\text {th }}$ ed. Washington: American Public Health Association, 1995. 1.193 p.

AYERS, R. S.; WESTCOST, D. W. Water quality for agriculture (Revised). Rome: FAO, 1985. 174 p. (Irrigation and Drainage, Paper n. 29).

BAUMGARTNER, D.; SAMPAIO, S. C.; SILVA, T. R.; TEO, C. R. P. A.; BOAS, M. A. V. Reúso de águas residuárias da piscicultura e da suinocultura na irrigação da cultura da alface. Engenharia Agrícola, Jaboticabal, v.27, n.1, p.152-163, 2007.

DUARTE, A. S.; AIROLDI, R.P.S.; FOLEGATTI, M. V.; BOTREL, T. A.; SOARES, T. M. Efeitos da aplicação de efluente tratado no solo: $\mathrm{pH}$, matéria orgânica, fósforo e potássio. Revista Brasileira de Engenharia Agrícola e Ambiental, Campina Grande, v.12, n.3, p.302-310, 2008. 
FAVRET, A. M. M. F.; CRUZ, R. L. Qualidade da água utilizada para irrigação de hortaliças na região de Botucatu - SP. Irriga, Botucatu, v.12, n.2, p.144-153, 2007.

FRANCO, R. A. M.; HERNANDEZ, F. B. T. Qualidade da água para irrigação na microbacia do Coqueiro, Estado de São Paulo. Revista Brasileira de Engenharia Agrícola e Ambiental, Campina Grande, v.13, n.6, p.772-780, 2009.

FRIES, J.; GETROST, H. Organic reagents for trace analysis. MERCK, 1977. 236 p.

GOMES, T. M.; MELFI, A. J.; MONTES, C. R.; SILVA, E.; SUNDEFELD JÚNIOR, G. C.; DEON, M. D.; PIVELI, R. P. Aporte de nutrientes e estado nutricional da cana - de - açúcar irrigada com efluente de estação de tratamento de esgoto com e sem desinfecção. Revista DAE, São Paulo, n.180 especial, p.19-25, 2009.

HEIDARPOUR, M.; MOSTAFAZADEH-FARD, B.; ABEDI KOUPAI, J.; MALEKIAN, R. The effects of treated wastewater on soil chemical properties using subsurface and surface irrigation methods. Agricultural Water Management, Amsterdam, v.90, n.1-2, p.87-94, 2007.

JOSÉ, J. V.; RIBAS, M. M. F.; FREITAS, P. S. L.; FRANCISCONI JÚNIOR, J. P. Efeito da aplicação de efluente de abatedouro bovino tratado em lagoas de estabilização no solo e no desenvolvimento do milho. Pesquisa Aplicada \& Agrotecnologia, Guarapuava, v.2, n.1, 2009.

LEAL, C. M.; ANDRADE JÚNIOR, A. S.; SOUSA, V. F.; SILVA, E. F. F.; BASTOS, E. A. Qualidade da água subterrânea para fins de irrigação na microrregião de Teresina, Piauí. Irriga, Botucatu, v.14, n.3, p.276-288, 2009.

MACHADO, P. J. O.; VALLE, G. M.; RINCO, L.; CARMO, L. F. Z.; LATUF, M. O. Qualidade das águas do Rio Paraibuna no trecho urbano de Juiz de Fora/MG. Revista Virtú, Juiz de Fora, v.1, 2005.

MARQUES, P. A. A.; FRIZZONE, J. A.; TEIXEIRA, M. B. O estado da arte da irrigação por gotejamento subperficial. Colloquium Agrariae, Presidente Prudente, v.2, n.1, p.17-31, 2006.

MEDEIROS, S. de S.; SOARES, F. A. L.; GHEYI, H. R.; FERNANDES, P. D. Uso de água residuária de origem urbana no cultivo de Gérberas: Efeito nos componentes de produção. Engenharia Agrícola, Jaboticabal, v.27, n.2, p.569-578, 2007.

MENEZES, J. M.; PRADO, R. B.; SILVA JÚNIOR, G. C.; MANSUR, K. L.; OLIVEIRA, E. S. Qualidade da água e sua relação espacial com as fontes de contaminação antrópicas e naturais: Bacia hidrográfica do Rio São Domingos - RJ. Engenharia Agrícola, Jaboticabal, v.29, n.4, p.687698, 2009.

MERCK. The testing of water. $9^{\text {th. }}$ ed. Darmstadt: Merck, 1972. 224 p.

METCALF, L.; EDDY, H. Wastewater engineering: treatment and reuse. $2^{\text {nd }}$ ed. New York: McGraw-Hill, 1991. 1.334 p.

NAKAYAMA, F.S.; BUCKS, D.A. Trickles irrigation for crop production. Phoenix: Agricultural Research Service, U.S. Water Conservation Laboratory, 1986. 383 p.

NOBRE, R. G.; GHEYI, H. R.; ANDRADE, L. O.; SOARES, F. A. L.; NASCIMENTO, E. C. S. Crescimento do girassol irrigado com água residuária e adubação orgânica. Revista DAE, São Paulo, n.180, p.50-60, 2009.

SANDRI, D.; MATSURA, E. E.; TESTEZLAF, R. Alteração química do solo irrigado por aspersão e gotejamento subterrâneo e superficial com água residuária. Revista Brasileira de Engenharia Agrícola e Ambiental, Campina Grande, v.13, n.6, 2009.

SANDRI, D.; MATSURA, E. E.; TESTEZLAF, R. Teores de nutrientes na alface irrigada com água residuária aplicada por sistemas de irrigação. Engenharia Agrícola, Jaboticabal, v.26, n.1, p.45-57, 2006. 
SOUSA, C. C. M.; BEZERRA, F. M. L.; MOTA, S.; AQUINO, B. F. Avaliação químicabromatológica e produtiva do capim Tifton 85 (Cynodon SSP.) irrigado com esgoto doméstico tratado. Revista DAE, São Paulo, n.180 especial, p.26-32, 2009.

SOUSA, J. T.; CEBALlOS, B. S. O.; HENRIQUE, I. N.; DANTAS, P. D.; LIMA, S. M. S. Reúso de água residuária na produção de pimentão (Capsicum annuum L.). Revista Brasileira de Engenharia Agrícola e Ambiental, Campina Grande, v.10, n.1, p.89-96, 2006.

USEPA. UNITED STATES ENVIRONMENTAL PROTECTION AGENCY. Guidelines for water reuse. Washington: U. S. Environmental Protection Agency, 1992. 252 p. 